\title{
The Wisdom of Adaptation of Dong's Traditional Residential Space Environment from the Perspective of Health- Ca Case Study of Gaoxiu Dong Village in Guangxi
}

\author{
Na Wang ${ }^{1}$, Wenjun Zheng ${ }^{1,}{ }^{*}$, Mengyao Tian ${ }^{1}$, and $\operatorname{Lin~} \mathrm{Li}^{1}$ \\ ${ }^{1}$ College of Tourism \& Landscape Architecture, Guilin University of Technology, Guilin 541004, China
}

\begin{abstract}
Healthy living space is the guarantee of high quality of life, dong Village is one of the few minority living space environment adaptation wisdom of the living carrier. By virtue of its healthy ecosystem and the smart wisdom of residents, it is connected with or adapted to the natural environment to create a healthy and livable living space under low-technology conditions. Taking The Gaoxiu Dong Village as the research object, this paper analyzes the environmental adaptation wisdom of the spatial elements such as road system, drum tower space and residential building in Gaoxiu Dong Village, so as to show the spatial form beauty, functional practical beauty and national characteristic beauty of Dong Village. From the perspective of health, it analyzes the adaptive form and mode of human living space, and inherits the wisdom of building with respect to nature and environment.
\end{abstract}

\section{Introduction}

Healthy China 2030 points out that we should focus on people's health, adhere to prevention, promote healthy lifestyles and create a green and safe environment. After thousands of years of tests, the construction of Dong villages has concentratedly reflected the harmonious relationship between the Dong ethnic group and the nature in order to survive and develop. Residents have formed a unique healthy living state and a highly resilient health space in the long-term continuous practice. With the emergence and development of public health problems, health-oriented living space emphasizes the importance of healthy living environment from ecosystem, environmental microclimate to wind and thermal environment treatment of residential buildings, and realizes the transformation from individual physical and mental health to individual and social health.

At present, most of the research on healthy people's living space is based on spatial function and environmental factors. Xie Jin, based on environmental behavior and demand theory, uses structural equation model to guide health and reasonably plans urban living environment conducive to residents' physical and mental health ${ }^{[1]}$. Tu Shuangshuang et al. analyzed the structural characteristics of different types of rural settlements through remote sensing image data and GIS space ${ }^{[2]}$. Some scholars tap the ecological practical wisdom of traditional villages. Wang Jingwen interprets the traditional settlement environment from the perspective of spatial syntax, and reveals the adaptability of settlement development ${ }^{[3]}$. Li Zhe et al. quantitatively analyzed the spatial form of streets and lanes in Dong traditional villages through field research ${ }^{[4]}$. In view of this, this paper analyzes the morphological characteristics and environmental adaptation wisdom of Gaoxiu Dongzhai's living space from the perspective of health by constructing three systems of living space, so as to improve people's value cognition of living space environment adaptation wisdom and the importance of healthy environment construction.

\section{Research Area and Overall Framework}

\subsection{Overview of the study area}

Gaoxiu Dong Village belongs to Sanjiang Dong Autonomous County of Guangxi, located in the upper reaches of Pingtan River. According to the mountains and rivers, ancient trees and heavens, it was built 500 years ago (Fig. 1). It is the birthplace of "Baili Dong Township Corridor". It has won the title of "National Ecological Civilization Village", "Guangxi Civilization Unit"and "Top Ten Beautiful Villages" in Liuzhou City, and has been listed in the first batch of Chinese minority villages and world cultural heritage. There are 408 households, a total of 1630 people. There are 9 drum towers and 3 wind-rain bridges. The stilted buildings with green tiles and white eaves are integrated with the ancient drum tower and the wind-and-rain bridge lying by the stream, creating a distinctive landscape of mountain villages.

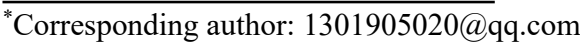




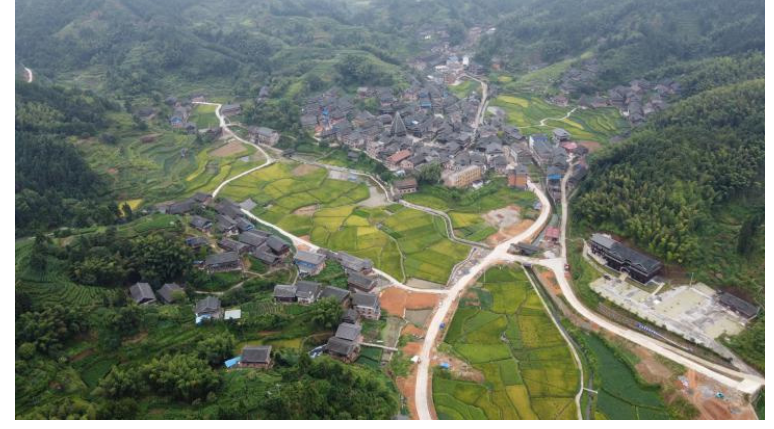

Fig. 1. Bird ' s View of Gaoxiu Dong Village

\subsection{Overall research framework}

The living space of Gaoxiu Dong Village is human-centered and health-oriented. It constructs three systems of environmental adaptation, health system and spatial characteristics, and refines"four adaptation wisdom". By analyzing the site layout, residential buildings, public space water adaptation, thermal adaptation, wind adaptation, light adaptation, to seek the "seven characteristics" of living space. The focus of environmental adaptation is to build a harmonious coexistence between environment and ecological health, physical health and mental health, to meet the material and spiritual needs of residents, and to create an ideal environment with ecologically sustainable healthy environment, aesthetic awareness and emotional identity (Fig. 2).

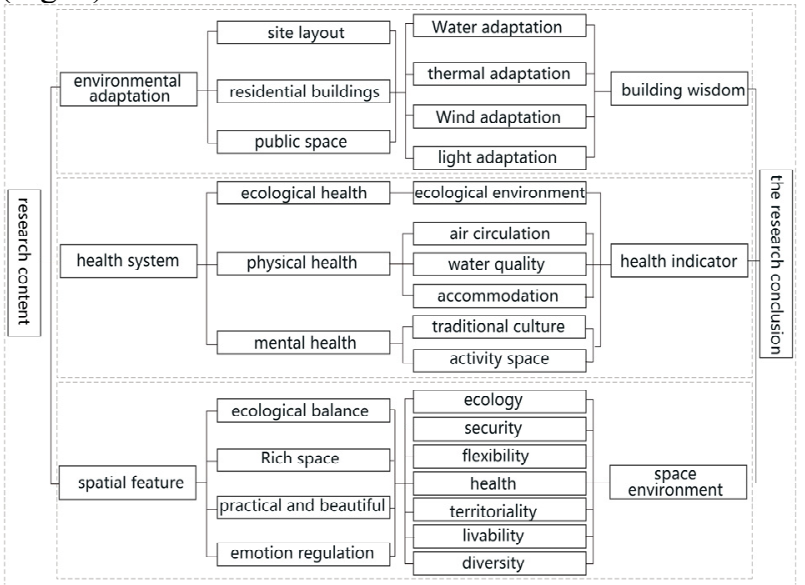

Fig. 2. Research Framework of Dong Traditional Living Space Environment Adaptation Wisdom from the Perspective of Health

\section{Environmental Adaptation Form of Gaoxiu Dong Village}

\subsection{Adaptability of location and layout of Gaoxiu Dongzhai}

Landscape natural environment factors are the dominant factors of village location and planning. The trend of the mountain often determines the layout form and spatial texture of the village. Gaoxiu Dong Village is a mountainous riverside landscape. The terrain in the village is high in the east and low in the west. The overall spatial pattern of the village is large scattered and small concentrated. Water system and cultivated land determine the distribution density and spatial sequence of buildings. Settlements are located in the open area of the north bank of the east-west river, and the high terrain on both sides of the north-south river, which is not easy to be attacked by flood. Residents in the limited resource space, take the initiative to use the laws of nature, location to the sun, choose water and build. Most of the residential buildings are located at the half mountainside, with excellent visual landscape, which is in line with the winding roads. In addition to building occupation, different crops are planted in concentrated and scattered farmland. The planting mode of climbing crops combined with artificial scaffold provides residents with rest space, increases crop diversity and beautifys settlement environment ${ }^{[5]}$. Multi-level and different types of land use forms are conducive to a virtuous cycle of soil, a variety of biological symbiosis, and efficient use of land resources(Fig. 3).

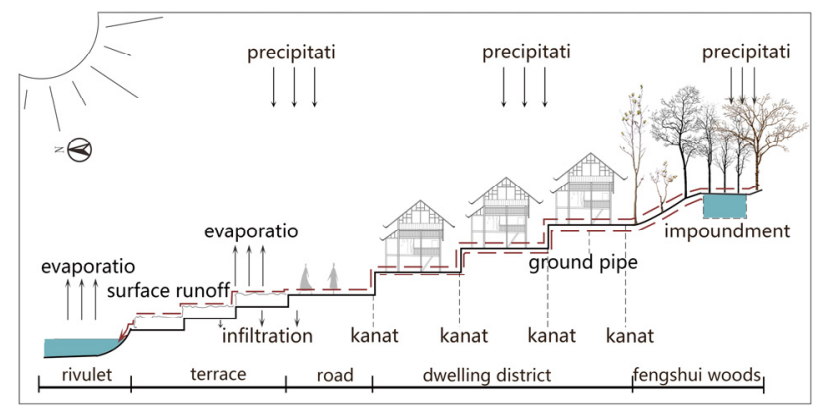

Fig. 3. Environmental adaptation analysis chart of Gaoxiu Dong Village

\subsection{Environmental adaptation in public space}

\subsubsection{Environmental adaptation of street space}

Apart from abundant spatial changes, building forms and street landscapes are more important to form ventilation corridors, improve air quality and reduce the probability of contact between pathogenic factors in the air and human beings ${ }^{[6]}$. The different spaces created by buildings and streets and lanes involve the accessibility of roads, different textures of ground materials and changes in laying methods from the sense of behavioral space, which can guide and prevent traffic ${ }^{[7]}$. People enrich their inner feelings and adjust their emotions by sensing the alternation of opening and closing, staggered and hierarchical spatial changes.

\subsubsection{Functional adaptation of drum building space}

Drum Tower not only carries office, ideological education, cultural learning and other functions, more importantly, as a spiritual support, inherited a generation of skills and environmental adaptation wisdom. The spatial layout of Gaoxiu Dong Village is compact and the available land is limited. However, there is still a large 
area of space before the central drum tower to meet the needs of people's major festivals and sports.

The height of the fire pond in the Drum Tower is lower than the ground level, fast ignition speed, long ignition time and fast heat release rate. The sunken fire pond is convenient for the collection of wood residue after burning, and it is not easy to destroy the clean interior space under the influence of external forces.

In order to meet the needs of people's production and life, the overall construction of drum building adopts hollow design, and the upper part of the attic adopts staggered floor design. The interior space of Gaoyan Drum Tower has two steps under the wooden fence to meet the functions of cooling and chatting on the wooden steps in summer (Fig. 4). In winter, fir bark and Dongjin cloth are used to surround the periphery of the drum building to avoid cold wind intrusion and maintain indoor temperature for a long time. Due to the good ventilation at the top, the burning harmful gases can be quickly dredged.

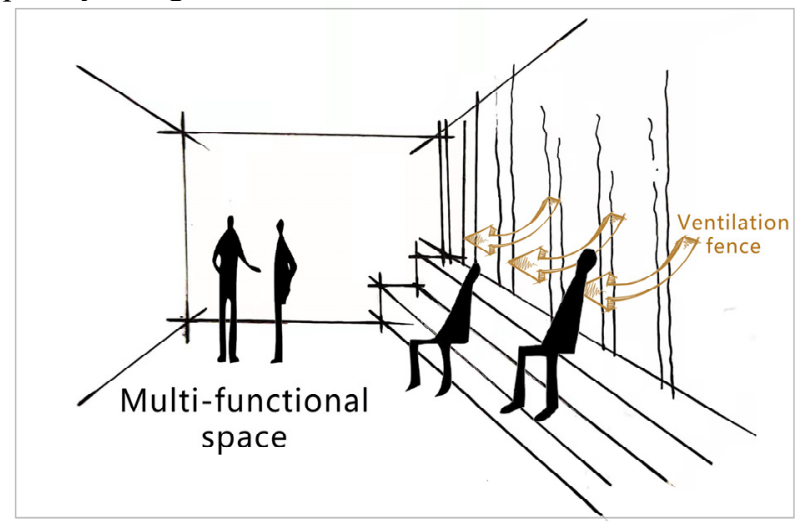

Fig. 4. Ventilation fence of high rock drum building

\subsection{Environmental adaptation of living space}

\subsubsection{Environmental adaptationof residential buildings to topography}

Building completion is the result of long-term adaptation of residents in past dynasties to the environment and ground transformation. In order to adapt to the terrain, the spatial form is constructed in the form of staggered floor, filling and digging, and hanging. In terraces and narrow irregular sections, site selection in accordance with mountain slopes. Due to the elevation of the living surface in the uneven terrain, the elevated column of the overhead can be freely and flexibly adjusted with the change of the terrain, which does not need to adjust the terrain greatly and has less damage to the natural landscape.

\subsubsection{Environmental adaptation of residential buildings to climate}

In the densely distributed areas of Dongzhai, the high temperature and sultry heat in summer, cold and humid in winter lead to dry railing buildings are more common in the south. The underlying overhead construction method is conducive to the construction of ventilation corridors, and guides the building layout to deal with the overall ventilation system. At the same time, save land resources, help to maintain indoor drying, away from mosquitoes. Corridor setting is conducive to avoiding summer heat, isolating cold wind in winter, lighting and ventilation, and strengthening indoor and outdoor air convection in coordination with doors and windows. The Dongzhai Corridor is mostly wrapped by fir bark. In rainy season, it can absorb water in the air, and in dry weather, it can release water, and it will not produce condensation water, which can adjust the humidity in the building. Most of the roofs are dominated by hanging mountains and hillsides. The overhead of the roof is conducive to the isolation of high temperature in summer. The selection of eaves and hanging feet makes the heavy eaves and drape eaves have the function of shading and rain (Fig. 5).

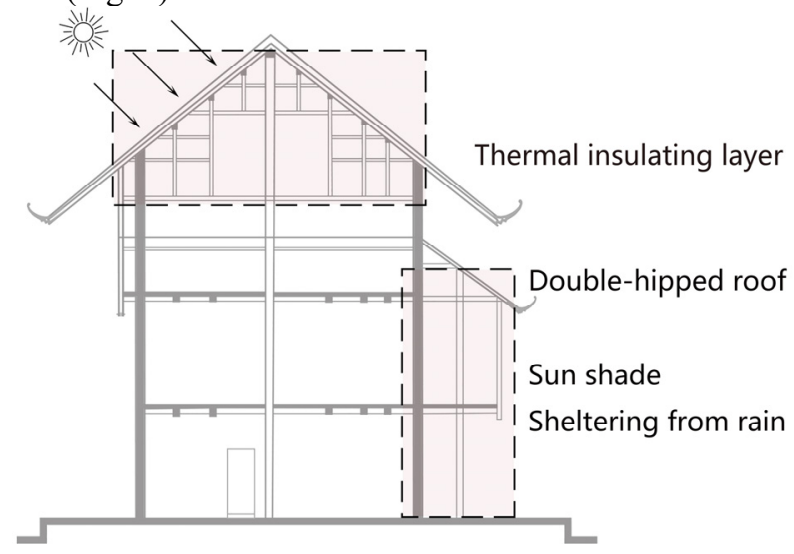

Fig. 5. Analysis of Shading and Rainproof of Residential Buildings
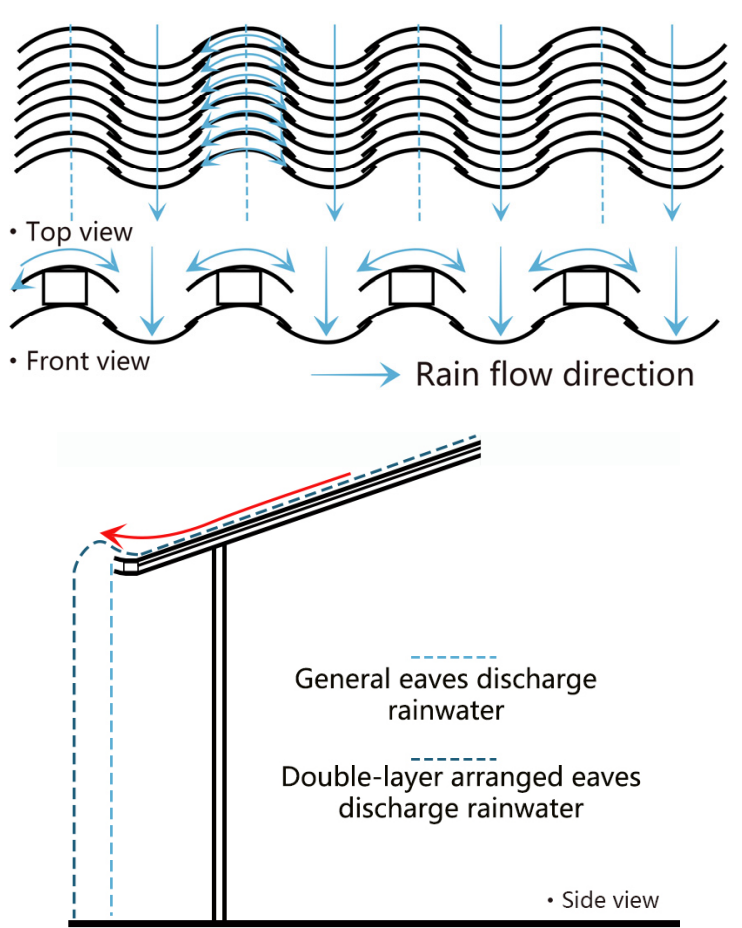

Fig. 6. Drainage analysis diagram of roof style

The arrangement of roof tiles' falling together is conducive to weakening the impact of rainwater on the 
roof. The horizontal and vertical simultaneous discharge of rainwater is conducive to the efficient dispersion of rainwater, reducing the length of stay, avoiding the damage of rainwater infiltration to houses, and extending the service life of roofs. The tiles are arranged in double layers at the end of the eaves, raising the tail to form a micro radian, which is beneficial to the rain to throw away further distances and reduce the damage caused by rain falling to the vertical wall (Fig.6).

\section{Healthy Living System in Gaoxiu Dong Village}

\subsection{Ecological health system}

The existence of life needs to be guaranteed by ecological security. The factors in the ecosystem interact and depend on each other, and the multi-functional structure system is reasonably regulated. Natural environmental factors, agricultural production factors and rural life factors provide a healthy ecological environment, diverse biological species and suitable landscape microclimate.

Dongzhai is rich in plant resources, and green plants can be used as the first line of defense to filter out large granular harmful substances such as dust in the air. The Dongzhai water diversion and drainage system combined with the terrain through the physical processes of rainwater's 'collection', 'infiltration', 'storage' and 'drainage'. It can be drained in rainy season, and water evaporation increases air humidity in dry season to balance the climatic characteristics caused by seasonal precipitation. Plant landscape can also adjust the carbon content above the settlement and improve the environmental quality, thereby reducing the risk of infectious viruses and bacteria caused by climate change and the migration of wildlife habitats, and realizing the control of infectious sources.

\subsection{Physiological health system}

\subsubsection{Air circulation and water quality health}

Gaoxiu Dongzhai builds a multi-level ventilation corridor system to further improve air quality. By adjusting the relationship between site selection and landscape, the site selection and layout can fully adapt to the terrain. Under the influence of wind direction, air circulation has fast monsoon circulation speed and high air exchange efficiency, which has a positive impact on eliminating harmful gases and improving air quality. Settlement water resources and irrigation ditches are in line with the situation. The water diversion system reduces the possibility of water infectious disease transmission by shaping the interaction between benign aquatic ecosystem and water adaptive landscape, as well as the decomposition and purification of organic matter in water by aquatic animals and plants.

\subsubsection{Environmental facilities}

From the perspective of environmental construction in Gaoxiu Dong Village, the public space layout of settlement centered on drum tower has been formed, which provides public service sites and activity sites for people, increases exercise opportunities, and highlights the importance of prevention-oriented healthy environment. Gaoxiu Dong village drum floor, for public health emergencies, can be used as a green space for disaster prevention. Residents walk or run through street space to ensure the minimum time limit for physical activity, or farming, fishing, tea harvesting and so on in the field can also increase physical exercise.

\subsection{Mental health system}

\subsubsection{Traditional culture}

The settlement of Gaoxiu Dong Village transmits its own culture and landscape characteristics through the configuration of living space, which not only provides the possible material basis for people 's social activities, but also provides a prerequisite for the creation of environmental adaptation wisdom. Through the inheritance and development of traditional construction technology, festivals and handicrafts, people express their sense of identity and praise for the cohesion of traditional culture.

\subsubsection{Activity space}

Settlement environment can have a direct impact on people, the most important is the aesthetic and spiritual level of value transfer. Gaoxiu Dong Village has formed its own stable green and healthy space through site selection and layout, creating favorable conditions for people to be close to nature. The public space dominated by practicality, diversity and aesthetics provides places for people to communicate and then creates a harmonious and harmonious living atmosphere in spirit.

\section{Characteristics of Living Space Environment of Healthy People}

The settlement location layout of Gaoxiu Dong Village conforms to the nature, and the spatial structure characteristics are significant. The architectural material selection originates from nature and the living environment is green. Site selection and layout adaptation, water environment adaptation and architectural adaptation constitute the characteristics of Gaoxiu Dongzhai, carrying the ecological logic and construction wisdom system of Dongzhai. The location layout of Gaoxiu Dong Village seeks the best living environment by dealing with the relationship between the factors such as mountain terrain, rivers and streams. Water adaptation improves human settlements through terrain elevation, slope, precipitation and evaporation; Building space enriches space form through building 
material selection, construction mode, layout and other elements; Street space, landscape pattern and architectural layout are complementary (Tab.1), and landscape facilities are practical and beautiful.Gaoxiu Dong Village makes full use of the subjectivity and regularity of human settlement space to coordinate the relationship between settlement space and environmental adaptation, pays attention to people's subjective emotions and regulates mental health.

Table 1.The overall analysis of environmental adaptation wisdom of Gaoxiu Dongzhai settlement space.

\begin{tabular}{|c|c|c|c|}
\hline $\begin{array}{c}\text { Space } \\
\text { type }\end{array}$ & \multicolumn{2}{|c|}{ Spatial feature } & $\begin{array}{c}\text { Environmental } \\
\text { adaptation } \\
\text { characteristics }\end{array}$ \\
\hline $\begin{array}{c}\text { Site } \\
\text { selection }\end{array}$ & $\begin{array}{c}\text { Landscape } \\
\text { pattern }\end{array}$ & $\begin{array}{c}\text { Near the } \\
\text { mountain } \\
\text { and by the } \\
\text { river }\end{array}$ & $\begin{array}{c}\text { Waterborne } \\
\text { Heliotropism } \\
\text { Ecology }\end{array}$ \\
\hline $\begin{array}{c}\text { Street } \\
\text { and lane } \\
\text { space }\end{array}$ & $\begin{array}{c}\text { Building } \\
\text { adaptation }\end{array}$ & $\begin{array}{c}\text { High and } \\
\text { low fall }\end{array}$ & $\begin{array}{c}\text { Diversification } \\
\text { Symbolic }\end{array}$ \\
\cline { 2 - 4 } & feeling & $\begin{array}{c}\text { Step } \\
\text { change }\end{array}$ & $\begin{array}{c}\text { Comfort } \\
\text { Convenient }\end{array}$ \\
\hline Public & $\begin{array}{c}\text { Functional } \\
\text { adaptation }\end{array}$ & $\begin{array}{c}\text { Functional } \\
\text { composite }\end{array}$ & $\begin{array}{c}\text { Uniqueness } \\
\text { Security }\end{array}$ \\
\hline \multirow{2}{*}{$\begin{array}{c}\text { Habitable } \\
\text { space }\end{array}$} & $\begin{array}{c}\text { Terrain } \\
\text { adaptation }\end{array}$ & $\begin{array}{c}\text { Hugging } \\
\text { the contour }\end{array}$ & $\begin{array}{c}\text { Flexibility } \\
\text { Diversity }\end{array}$ \\
\cline { 2 - 4 } & $\begin{array}{c}\text { Acclimatiz } \\
\text { ation }\end{array}$ & $\begin{array}{c}\text { Diversified } \\
\text { forms }\end{array}$ & $\begin{array}{c}\text { Territoriality } \\
\text { Livability }\end{array}$ \\
\hline
\end{tabular}

The health and livability of the spatial environment are the basic attributes of the human settlement environment. The local landscape with strong safety and adaptability is integrated with the activities of residents. A comfortable and flexible traffic environment can form a good interaction between residents and environmental factors, and increase the probability of residents ' outgoing activities. The suitability of activity space is the primary choice of residents' communication activities, and the convenience of facility activities is the driving force of activity. The safety, convenience and functionality of the health system, the comfort and sense of belonging of the environment to adapt to the wisdom, as well as the rich landscape space, the layout of multiple and complex fitness facilities, and the traditional residents ' culture jointly construct the wisdom of Dongzhai settlement and build a healthy living environment.

\section{Conclusion}

This paper reviews the relationship between health system components, environmental adaptation wisdom and spatial characteristics. The subjective perception and psychological satisfaction of residents ' personal needs, travel modes and physical activities on the needs of living environment are the systematic support of healthy living space. The living space and environmental adaptation wisdom of Gaoxiu Dong Village show a close collaborative interaction in the evolution of history, which is of enlightening significance for the efficient construction of healthy living space and the protection of residents ' physical and mental health.

\section{Acknowledgments}

Supported by: Humanities and Social Science Youth Fund Project of Ministry of Education of China (19YJC850027);

Supported by: National Natural Science Foundation of China (51968012);

\section{References}

1. J.Xie,M.H.Quan,E.L.Xie, CPR, 44, 48-54(2020)

2. Y.Y.Tu, EG, 39, 142-149(2019)

3. J.W.Wang, AJ,39, 58-61(2010)

4. Z.Li, J.Y.Yin, COA, 2019(03), 107-109(2019)

5. S.G.Peng, LA,27(9), 77-88(2020)

6. X.L.Liang, AC,2020(08), 168-169(2020)

7. C.Y.Hao, UAA,17(18), 28-29(2020) 